\title{
Hermenuticals of Human Movement and Sport: Holism and Harmony
}

\author{
Authors' contribution: \\ A) conception and design \\ of the study \\ B) acquisition of data \\ C) analysis and interpretation \\ of data \\ Ivo Jirásek ${ }^{A-D}$, Emanuel Hurych ${ }^{A-D}$, Josef Oborný ${ }^{A-D}$ \\ Palacký University, Czech Republic \\ Masaryk University, Czech Republic \\ Comenius University in Bratislavia, Slovakia \\ D) manuscript preparation \\ E) obtaining funding
}

ABSTRACT

\begin{abstract}
The paper deals with the hermeneutical approach to active human movement and sport. This topic has been more frequently examined in literature since 2010. This paper focuses on holism and harmony within the hermeneutics of sport. Some specific holistic approaches based on different viewpoints are described here. The key task of the middle part of the paper is to question and search for authentic meanings in sport. In this context, the theory of kinestructs and kinascepts by Eleaonor Metheny is briefly explained. The final part of the paper attempts to summarize possibilities for uncovering a deeper sense of human movement in the context of holism. authenticity, kinescept, kinestruct, kinesymbol, levels of satisfaction
\end{abstract}

KEYWORDS

\section{Introduction}

The philosophical concept of hermeneutics presents the opposite pole of human mental activities from positivism. While positivism focuses on facts that are objectively established (everything that can be measured, weighed, and expressed in the quantitative outputs of scientific research), hermeneutics uses qualitative approaches of scientific research. The aim of hermeneutics is not to give an explanation, but to reach an understanding.

This approach was originally based on the textual and contextual critics of the Bible, and was later applied to possible interpretations of any text. It is perceived as the "art of interpretation" (HERMENEUEIN $=$ to clarify, to interpret), which became a broader basis for human psychic interpretations and now presents the key means of the culture of human sciences methodology. In a general sense, we can speak about hermeneutics in the context of the ancient Greek culture (the first interpretations of the works of Homer). In a narrow sense, we can speak about the beginnings of hermeneutics in the context of the nineteenth century, when the first thinkers started to become interested in the "science of understanding." The first personalities who could be considered as the founders of hermeneutics were Friedrich Daniel Ernst Schleiermacher, Wilhelm Dilthey, Hans-Georg Gadamer, Paul Ricoeur, and Karl-Otto Apel.

Understanding, as a kind of knowledge that cannot rely on descriptions and explanations alone, is delimited as a form of movement within the circle that includes some very individual phenomena (a word, text, event, experience, etc.) and a complex horizon of its meaning. Each phenomenon is understandable just from the position of the whole, as the whole is approachable just through the separate phenomenon. The hermeneutic circle expresses some of the (essential) relational closeness of the concept. However, the 
impossibility of escape from this circle does not present a handicap for understanding here. That is why any partial understanding is included in the frame of pre-understanding. And pre-understanding is not closed. It is open for new deepening and the adjustment of the contents of meanings. However, the context of these meanings can be found inside the circle, and we cannot bring it somewhere from the outside.

Searching for some technically based methods led to the descriptions of the hermeneutic circle as the circular movement of understanding with repeating turns from the whole to the parts and back. Martin Heidegger perceives the hermeneutic circle as the expression of an existential pre-structure of the human being. Despite the critical comments of some thinkers who express the danger of entering the circle, he emphasizes the necessity of entering it in the proper way (Heidegger 2008). The hermeneutic circle presents an abstract model construction. That is why some authors have tried to model some different geometrical projections of it. Oeming (2006) speaks about "the hermeneutic quadrangle," whose apexes are author, text, reader, and thing. Bednár (2009) argues that it is more exact to use the terms "the hermeneutic circulation" or "the hermeneutic ring." Both of these terms provide us with greater content freedom. In the context of evolution and its role for the development of mankind, some authors (Oeming 1991; Hendl 2005) accent the effort to catch the possibility of motion in the Hegelian way in the form of "the hermeneutic spiral."

\section{Hermeneutics as a possible path towards a deeper understanding of man in motion}

The hermeneutic approach to the world is more and more often applied in the philosophy of sport (or in philosophical kinanthropology). Even in the 1980s, the topic of the priority of "clarifying" or "criticism" in the hermeneutic approach was discussed by Crum (1986) and Hawkins (1987) in the Journal of Teaching in Physical Education.

Even before this, Harris tried to describe the specifics of the hermeneutic approach to research in the field of sport in this way:

From the perspective of hermeneutics, both culture itself and the research processes by which culture is studied are considered to be constituted partially by shared meanings (...). Although hermeneutic cultural research is not free of criticism, studies concerning games and sports which have been carried out within this mode of investigation (...) indicate that this research process has good potential for use by scholars who wish to broaden their understanding of these phenomena. (Harris 1981, p. 72)

Hermeneutics relates to the topic of corporeality as well. This relationship can be expressed as a kind of "physical understanding." On the other hand, there are many aspects that can support the humanistic role of sport (Oborný \& Vrtiaková 2014). In some situations, when people enter the roles (of actors or sports competitors), something like "listening to one's body" can be seen. For this phenomenon, metaphorical expressions are very often used (like "feeling the snow" in skiing, "reading the game" in soccer, etc.). The understanding thus gains its "scenic character" (Jurkevič 2002). Some aesthetic aspects of the perception of motion can also be measured (Pačesová 2014).

Physicality expressed by entering the roles accents a strong possibility for a hermeneutical approach to sport that consists in the interconnection between sport and art. Edgar explores the relationship of sport to art:

"I will argue that sport is about something. I will draw a comparison between sport and music, and use the analytic and hermeneutic methods that have been developed to interpret music as a clue to the interpretation of sport" (Edgar 2013, p. 140).

Edgar does not argue that sport is one of the arts, but rather that sport and art hold common ground. Both are ways in which humans confront philosophical challenges, though they do this through very different media.

The hermeneutic analysis of internalism, as the traditional discourse in American philosophy of sport (presented by Bernard Suits and his successors), was provided by Frias and Monfort (2015). Their critical comments concern "four consequences of following such a prejudice: 

a) its reductive nature,
b) the production of an unrealistic view of sports,
c) the vagueness of the idea of excellence; and
d) the leap from the descriptive analysis of the sporting phenomenon to the setting of normative requirements for the practice of sports" (Frias \& Monfort 2015, p. 5).

In conclusion, we can say that, especially since 2010, many authors have paid increasing attention to the hermeneutic approach to some kinanthropological problems. A recent Sport, Ethics and Philosophy special issue introduced by Frias and Edgar (2016) titled Hermeneutics and Sport (2016, Vol. 10, Issue 4) was completely devoted to the topic of hermeneutics in sport.

\section{Holism and harmony: The meaning of human (sport) movement}

Philosophy is a kind of questioning relating to the whole and its complexity, which reflects a significant difference from the knowledge developed in the sciences. The whole is mostly considered to be a sum of the partial components. Then the compact whole is presented as a kind of interconnecting of some independent segments (spare parts) that are in primary relation to the whole in the ontologic, epistemological, and axiological meanings. However, this is not the only possible way to understand the whole. No matter how successfully this method is applied in the sciences and in the technological way of thinking, it has quite a low level of relevance for philosophy and loses its functionality.

The whole, indivisible to segments (which is not a priori understood as a sum of components), is related to the Greek term HOLON (from Greek HOLOS = wholeness, and suffix ON = a part). Unlike the previously described meaning - a separable whole (coming from the Greek word PAN) - "holon" presents that manner of perceiving complexity that can provide (in the philosophical analysis of the intentional human movement) the only meaningful method of thinking of the mutual relations and consequences concerning the body and mind. Those who prefer exploring the whole in the concept of the Greek PAN can investigate some parts of the human body as functional segments. For some scientists, it makes sense to explore an isolated part of the body (e.g., a skeleton, or a digestive system) because via this separation the specifics of the researched object and distinctness of the analyzed segment increase. The human being is thus divisible into segments in the context of anatomy, or physiology, and can also be explored within some sociological aspects (per the roles that are played in society).

For those who prefer an examination of the whole (HOLON), man/woman presents an indivisible complex. This complex approach predominates over any rational analysis that divides man/woman into his/her partial components. Or better, perhaps nobody understands the possibility of the division of the human body into something other than a rational discourse (a hand separated from the body is not considered to be an independent unit, in fact). Nevertheless, in the sphere where these examples are not as obvious as the previous one, in the sphere of the separation of the body and mind, the segmented approach to the human body is not taken as an inadmissible triviality, but is practically considered to be a legitimate approach. This is the reason why the supporters of the holistic approach to reality prefer applying the approach to the whole based on HOLON and see it as being more meaningful. And this attitude is reflected in our approach to many of the explored topics in which the solution of the methodical process cannot be repeated (Kretchmar 2005).

Holism has not only an ontological dimension, but an epistemological status as well. Modern physics, humanistic and transpersonal psychology, phenomenology of religion, and a lot of other ideological streams display the necessity of a new relationship between the human and nature, as well as the necessity of a redefinition of scientific knowledge (to unite the humanities and sciences and to unite the scientific and religious approaches to the world).

All the parts of the whole must be in mutual harmony (in order for us to speak about the whole). The idea of harmony comes from the sphere of music. Firstly, it came there via the inclusion of Pythagoreanism into cosmology and anthropology (for them the human soul should be in harmony with the cosmic accord). 
Nevertheless, harmony keeps its original sense - rhythm, composition, and accord of all (sometimes dissonant) tones - and presents an analogy of the harmony of parts contained in the whole that is composed of them. However, there is one more feature of the whole: it can accept opposites and contain inseparable complexity. Nicolaus Cusanus speaks of coincidentia oppositorum (Hay 1952).

The explanation of the whole can be also provided via the phenomenon of pain and suffering in sport (Jirásek \& Hurych 2012). There are at least three possible approaches for dealing with this topic (Loland 2006). Thus, we can research pain using these approaches:

The scientific (medicine) approach. This approach understands pain as a physical phenomenon. Within the Cartesian approach, we can divide physical (res extensa) and mental (res cogitans) substances. This concept presents the separation of the body from the mind, and thus pain is understood as a process that informs the higher centers of the organism (brain) about a physical danger (injury, illness, etc.).

The constructivist approach. This approach takes pain as a product of the social and cultural context, of historical and social conditions. Society and its schemes determine what pain is and provides some ways to overcome it (the native tribes: initiative rituals as a symbol of the journey and transition to a different understanding).

The phenomenological approach. Pain is an existential topic here. We inquire as to the meaning and purpose of pain. The key role in the process of perception is played by experience, but this does not mean that the result is presented by a subjective opinion or illusion. There is a strict and exact method for considering the meaning of pain via the phenomenological reduction.

The meaning of the term of the whole is closely related to the understanding of the term "meaning." Meaningful activity has value in itself and can be considered an authentic experience. Thinking about the possibilities of uncovering the meaning of a human being via movement activities, we must urgently ask as to whether (or how) some partial topics are related to the phenomenon of the "life meaning" (sense of life). The question leads us to search for meaningfulness in some separate fields of our exploration (or in some partial activities). The meaning of the human way of being can be investigated via the sense of a cultural subsystem of movement culture, via the sense of human movement and via the sense of some concrete movement activities.

Trying to find a solution for how to interconnect these aspects, we fall into a kind of hermeneutic circle because we must admit that the sense of the human way of being can be explored via the sense of concrete activities, and also the sense that these activities should relate to the whole of the human being. The relationship between the concrete and the general, and between the part and the whole, gains its specific meaning and some dramatic features thanks to its search for sense and meaningfulness in our behavior and our actions (this can also be seen in the case of movement activities).

\section{Searching for the authentic meaning of movement}

The main question of our research is: Can searching for meaning contained in something transcendent present an acceptable alternative to the sense of life? This transcendence need not be included in something that is evidently outside our personalities. Could we accept looking for some selected outer symbol (happiness, pleasure, joy, or creative actions and work) as the sense of life? Is this sense also included in some object (idea, value) that our thinking is intentionally related to?

Or, is it necessary to search for something immanent? Could we explore the sense of life in the frame of life itself? Does any experience (of God, but not God himself; of work, but not work itself; of play, but not through playing a game) present the process of uncovering the experience of some (e.g., sport) performance which is endowed with the sense? Can the sense be seen not in the object of our intentionality but in the process of acting? 
The Czech philosopher Milan Machovec (Machovec 2012) describes the following possibilities for searching for the solution to the question about the sense (in a historical context):

The religious answer - Different religious concepts look for the sense contained in something outside us. This category of the outer sense can be taken in a personal way (God, or Gods) or in an impersonal way (Karma, Tao, law). In this period, we can see some feelings of existential "hungriness" that support trends towards some spiritual and religious streams. The question arises as to whether this effort is based on a deep and experienced belief (in its intrinsic perception). Undoubtedly, it presents a reaction to the trend of secularization in our society and a focus on buying non-essential things.

Pleasure and delight coming from carnal instincts, but also coming from the status of wellness provided by spiritual values (art, literature, etc.). Even if we did not satisfy ourselves with hedonism on the animal level (sexual pleasure, delight from good food, etc.) and rather aimed to consume some cultural achievements (provided through literature, theater, movies, or TV), we would still stay in the position of mere consumers. To keep the meaning of life in mind, we should not rely just on delights and pleasures whose character cannot be stable and permanent, in principle. At the same time, at least sometimes, we should be able to do without these pleasures in order to avoid becoming dependent on them.

Resignation of the possibility to find the meaning of life. This is represented by refusing all the previous conceptions of meaning. Moreover, it represents a kind of a protest against these concepts. A high rate of skepticism dominates in the situations of individual effort that are hopeless, desperate, and tragic.

In the sphere of movement culture, all those alternatives can be considered legitimate. However, we must ask: Can sport be promoted to the position of "God"? Can a competitive movement activity contain a sense of human life? Does pleasure from victory present the highest value that can be reached? Can any sense be seen in the life of a sportsman/woman who has finished his/her active career? Can a sport be perceived as a means of interpreting the sense of life? What is the real sense of a movement activity for humans?

The answers should be sought in the framework of the phenomenon of the authenticity of the human existence. The term "meaning" presents a central category in the psychotherapeutic concept of logotherapy (a kind of psychotherapy based on the restoration of sense) developed by Viktor Emanuel Frankl (Frankl 1988, 2006). LOGOS (an ambiguous term coming from Greek philosophy) is interpreted by Frankl as a sense that is understood as a requirement of the spirit (that ontic layer of a personality that desires to find a sense). That is why the possible absence of sense is not an issue of the soul (PSYCHÉ), but the spirit (LOGOS). Despite this fact, psychology (to follow its name) should respect both parts of its name (LOGOS, as well as PSYCHÉ).

Searching for meaning with the aid of psychotherapy is not a sign of mental disease, but of spiritual deprivation (the existential vacuum). The feeling of a loss of sense comes from different social pressures. They reflect a kind of surfeit that satisfies our needs and creates new ones. Surfeit (and not just material) is demonstrated in a permanent wasting and replacing of goods with newer and newer things while the older ones are left unused. It means falling into the short-term fashion trends that can be understood within Haideggerian analyses of Dasein (Heidegger 2008) as an inauthentic way of life, realized in impersonal "The They." The same can be said about the flood of information (books, journals, internet sources), the majority of which is completely useless and unimportant. A surfeit of experience situations can also be registered. The offerings of some "adrenaline" events (connected with movement activities) are mainly related to moments of short-term pleasure, illusions of intoxication from dangerous situations, and escapes from boredom and emptiness.

Frankl (2006) considers an effort for finding a sense (or better, will to sense) as a very strong motivating power that is somehow the opposite of the principle of pleasure or power. Meaning can be understood as the value of performance (activity or productivity, an effort to act or produce something that increases the level of human dignity), as experience (love, empathy, contemplation in the form of emotionality), or as attitude (a patient honesty in the moments of pain and suffering, resistance to hopeless situations, or acting heroically while accepting the strokes of fate). Logotherapy follows human life in a complex manner; it does not lift just the "meaningful" moments from the context (e.g., self-realization through the working process), but tries to 
find meaning even in suffering (provided it is inescapable) if it can be transformed into a kind of performance (e.g., into sacrifice). It presents the awakening of our responsibility.

Meaning is not anything abstract that can be felt in the same way for all people. It is not anything objective and scheduled. It is always unique and individual. It is grounded in the specific personal spheres of human attitudes and acting. It does not lie somewhere in front of us, which becomes apparent after the uncovering of some barriers and obstacles. We cannot reach meaning through an intentional process when we decide to select some activity or attitude in order to find it. Meaning comes as a side-effect of self-realization, or better, a side-effect of self-transcendence. The essentially personal attitude (love to a beloved person) or existential experience cannot be set up in a rational way. A decision to love a concrete person in order to gain a sense of life cannot lead to this aim (= meaning). In fact, it works exactly in the opposite way: by experiencing a kind of relationship that is mutually enriching and does not love as a calculated task, I can realize my love and aim for the sense of life despite planning and delimiting it. Meaning is included in the existential sphere.

A category of meaning is also related to language, or more specifically, to the discourse in which meaning is being sought after and discovered. The discourse is interconnected with human communication, as well as other activities of human beings in the world since it presents a reference frame for verbal and nonverbal methods of communication. The discourse relates to all the activities that create meaning and sense, despite the fact that they are positioned on the intentional, rational, unconscious, or reflective level. Movement activity as a cultural practice is set into the discourse of kinanthropology. This creates the meaning of the specific aspects of human existence and social life (Kirk 1992). A part of this discourse consists of physical literacy (Charles 1996), based on understanding the symbolic meanings of human movement.

Considering meaning as a demand for human behavior (as a specific possibility to decide upon with respect to existence, which enables transcendence), we can approach movement culture and its separated manifestations. What is the meaning of movement? Is there any general intrinsic meaning of the cultivated human movement? If the meaning does not present any transcendent category, but must be explored within movement itself, we must be led by its context (Seipel 2006). The circumstances, structuralization, and conditions of the movement itself create its meaning in some way. A form of movement gives evidence for the plasticity of a personality and speaks about individual, generational, and racial specifics. The context determines conditions for adequate interpretation of movement, which can be perceived on the level of a cultural symbol. Human movement is endued with symbolism. An effort to understand movement as a symbol can lead to diverse interpretations and attempts to prove those interpretations in a theoretical manner. However, this process is not based on language analyses, but on the evaluation of movement abilities and skills.

\section{Kinestructs, kinescepts, and kinesymbols}

A significant, not very celebrated, but inspiring theory of the meaning of movement is asserted by Eleanor Metheny (Ellfeldt \& Metheny 1958; Metheny 1964, 1967). She comes from the premise that the sense and meaning of movement (as an experience perceived in the somatic way) can be conceptualized by the human mind. The difference between a human and an animal (in the sphere of movement) consists of the human ability to think about movement and to transform our kinaesthetic perception of movement into some specific meanings. These enable us to find meaning in movement, which enables us to live in a different (symbolic) dimension of reality. Concerning language and speech, this ability for the symbolic transformation of the perception of various objects is evident in the use of words that present symbols for terms and meanings. The ability to transform sensory stimuli contained in the abstract idea establishes the background for creating the theory. However, not all kinds of symbols can be transformed into language. An example here is music. Music presents a method for the symbolic formulation of nonverbal sounds. Another example is a picture whose meaning cannot be fully contained in words because a visual symbol of a picture must be taken into a much broader context. A symbolic naturality of language can also be seen in poetry. Some symbolic transformation of movement is contained in dance art. Anywhere we meet symbols, we also meet meanings. 
Metheny argues that (not just) in the case of dance, a fundamental human ability to transform movement (kinaesthesia) as a general form of basic human experience into non-discursive conceptual symbols is present. For clearer understanding of these symbols, she creates a specific vocabulary that can help identify all the elements common to all the forms of human movement. Then she adds (for structures, perception, and conceptuality) three neologisms based on the Greek term KINEIN. The first one is the "kinestruct." It describes a dynamic form of continuing changes in the muscle tonus of a human body in motion. The second term is the "kinescept." It is understood as a sensory form established by the kinaesthetic perception of kinestruct. The interaction between kinescept and kinestruct, demonstrated as the coordinated answer of a personality to the individual interpretation of the stimulating situations, is called kinestructuralization. The last neologism is "kinesymbol." It presents a conceptualized form that gives evidence to the abstract significance and importance of kinestruct and its kinescept in the frame of the psycho-somatic-social context of the situation. Movement perception is thus transformed in abstraction, which can be seen as a symbol of meaning that is given to the perception of a concrete person.

This kind of conceptualization of kinaesthetic perception cannot be expressed in the symbols of any other biological (animal) species. It is not verbal, visual, auditory, or of any other kind of sense - it is kinaesthetic, a kinesymbol (the abstraction of movement experience) that is not recognized by the conscious. The kinescepts of similar kinestructs have very diverse emotional and intellectual meanings for different individuals, depending on the meaning that means experience in a concrete situation. For instance, different perceptions of the same movement segment (e.g., bending the knee during a jump) by a footballer or ballet dancer are the result of different meanings and connotations of the situation, which has no analogy in the comparison of both movement actions.

Although Metheny's theory was not generally accepted (the described neologisms are not in common usage), it provides a substantial possibility to understand our movement activity as a cultural and symbolic form of the personal manifestation that is endowed with meaning and sense. The formulation of the original perception of our movement is not transposable into any other forms of perception and presents a permanent ideological contribution. If a kayaker "reads" the river, or a swimmer "feels" the water, this could be expressed in the form of analogies and metaphors. Perception of movement in a concrete situation is non-transferable into any cognitive forms and is well expressed in the idea of a kinesymbol. Kinaesthesia (movement experience) can be experienced on the level of sense and values, and can be identified as a part of the human mentality, as a way for us to understand ourselves and the world, and it can be recognized as an essential part of the human way of being. If we try to explain what in the movement culture can enrich philosophical thinking, we can offer the previous ideas as a possibility for reflecting human movement in the context of the sense of the human being.

\section{The sense of human (sport) movement}

The holistic approach in the context of kinanthropology (or sport) has become quite an urgent topic during the past few years. Two issues of the journal of Sport, Ethics and Philosophy (from 2014) were devoted to the holistic approach to sport. Their author, Jesús Ilundáin-Agurruza, examines the contribution of some significant thinkers (John Dewey, William James, José Ortega y Gasset) to the holistic understanding of sport. $\mathrm{He}$ also deals with the possibilities of the holistic approach for the cultivation of sport settings, discusses developing "excellence" in sport, and brings up other topics, like social practicing in sport, "choking" in sport, etc. (Ilundáin-Agurruza 2014).

This structuring of meaning can be applied to the problem of the meaning of life. Movement is just a component, an agent, and perhaps a kind of means for the realization of meaning in human life. However, because it is not separable from human life itself, the described theory of meaning is functional for movement as well. More complicated situations can be seen in the understanding of sport in its institutional form (McFee 2013). Considering the existence of impersonal layers of meaning, we can conclude that a personal layer is 
influenced by other layers. Not only is a person an agent of accomplishing the meaning of movement, but there are more interconnected factors here.

The common intersection of meaning and movement in the philosophical context uncovers some strong and weak points of this interconnection. Our activities can have sense, even if they are meaningless, or perhaps purposeless. A typical example is Sisyphus' task of rolling a stone up a hill. His movement presents a necessary but nonsensical action. This mythological story has inspired a great deal of consequent considerations. Albert Camus, in his 1942 essay The Myth of Sisyphus, saw Sisyphus as personifying the absurdity of human life. Camus concludes that the image is one of a happy Sisyphus: "The gods had condemned Sisyphus to ceaselessly rolling a rock up to the top of a mountain, whence the stone would fall back of its own weight. They had thought with some reason that there is no more dreadful punishment than futile and hopeless labor" (Camus 1955, 119).

Camus is interested just in this moment of decision when Sisyphus wants to break his destiny: "That hour like a breathing-space which returns as surely as his suffering, that is the hour of consciousness. At each of those moments when he leaves the heights and gradually sinks toward the lairs of the gods, he is superior to his fate. He is stronger than his rock" (Camus 1955, 121).

When Sisyphus decides to accept the nonsensical task of staying on top of things, he becomes a winner for Camus: "The struggle itself toward the heights is enough to fill a man's heart. One must imagine Sisyphus happy" (Camus 1955, 123).

Undoubtedly, there is a bit of the naming and shaming strategy and countenance included in this decision. Sisyphus' movement misses flexibility and inventiveness and originality, as well as creativity in looking for ways to climb up. Despite this (and, of course, despite all the sins that he made during his life), his story became very inspiring for many other writers as well.

Different forms of human movement have different carriers, actors, and consumers. The same kind of movement can be seen in many different human activities, and just after we connect the movement with the purpose and circumstances of the activity, we can evaluate its contextual substance and meaning. A footballer or basketball player deal with the ball in a very similar manner as a circus performer, and a policeman who resolves a fight in a football stadium uses similar techniques as a martial arts competitor.

Some analogies in the sphere of art are under examination of authors in the field of philosophical kinanthropology. Kosiewicz (2009) speaks about similar movement elements that can be followed both in theater and in sport. The acting sportsmen create some specific scenic acts. Many dynamic and complicated movement forms of sport present a kind of show (volleyball, rugby, martial arts, sports gymnastics, etc.). There are many situations in sport that can be described as theater (not just theatrical) and deserve to become a topic of future studies.

Different forms of movement do not concern just the body. Even considering partial participation in sport, we must remember that sport is a sophisticated activity that contains some challenges aimed at the human spirit related to ethos. Movement expresses the dynamics and status of the whole human personality. That is why, in the context of rhetoric and etiquette, we speak about "body language." Movement touches everything that is hidden inside a human and that sometimes leaks out. Thus, movement is connected with mood, attunement, ideas, feelings, and emotions. We can say that the phenomenon of movement gives evidence of our mental movements (Hodaň 2000, 105). Movement is also the language of a mute or silent body.

\section{Conclusions}

Finally, we would like to summarize the topic of holism and harmony in sport through the search for a relationship between the meaning of sport movement and the objective and subjective needs of life. We can construct the basic structure of the relations and their levels as such: 
A level of satisfaction of the need of animal (biological) instincts, the sublimation of sensuous feeling (joy or anger) that (sometimes) contains a demand for fights and brawls. It is an elementary and authentically anthropological layer of meaning, and often manifests itself as a subconscious layer reflecting the meaning of movement in sport. Its "shots" outside can often be critically felt by an intellectual spectator, or by some indifferent public whose members do not feel any empathy towards sport. The Slovak philosopher Němec speaks about an ancient Greek storyteller (a famous author of fables), Aesop, who belonged to the opponents of the agonal competition. Aesop criticized the admiration of the athletes' power and considered demonstrations of their abilities as a kind of behavior with analogical reflections in the world of animals (Němec 2010).

A level of satisfaction of a broad range of human biological needs via movement actions. The rate of necessary human movement activities has rapidly decreased in the Euro-American cultural zone over the past few decades (Hurych 2010). This situation evokes a necessity to replace this insufficiency with new (and, for the most part, somewhat artificial) forms of human movement.

A level of satisfaction of some psychological needs. Here we can speak about spontaneous demonstrations of joy, pleasure, or disappointment, as well as overcoming fear from some movement activities, and some (previously mentioned) cases of sublimation of brutality, hostility, and violence.

A level of satisfaction of our hedonistic needs. Here can be included perceptions of pleasure provided by higher levels of endorphins - endogenous opioids (as a result of a natural pharmacological activity of the human organism) produced during (especially aerobic) movement activities. The need for producing the feeling of pleasure, delight, and wellness can be under the process of satisfaction via sport activities. Among recreational runners, there can be found a great number of experimenters, practical jokers, or risk takers who participate in some event because they want to satisfy their hedonistic needs (Mikihiri, Jordan, \& Funk 2015).

A level of satisfaction of eudaimonic needs. This includes the feeling of happiness and satisfaction that comes from the power of one's will or from the spectators' admiration (as well as the admiration of rivals, friends, schoolmates, parents, relatives, etc.).

A level of satisfaction of existential needs. This can mean looking for the answers to some questions like "Who am I?" and "What are my maximal limits?" or "Where is the border between staying healthy and saving my life?" This level can be explained through the examples of endurance sports. Two (of the three) authors of this article have personal and practical experience with marathons (and similar races) where dilemmatic situations on the edge of the physical and psychical possibilities of the organism sometimes present an unavoidable part of the race. These may include questions like "Should I give up, or should I walk (crawl) to the finish?" Sometimes giving up can present the only sensible option. On the other hand, this can be understood as a kind of humbling and faint-hearted choice.

A level of satisfaction of the philosophical and metaphysical needs. Within a general understanding crossing different philosophical discourses this can be presented, for instance, in getting in harmony with nature (in the case of outdoor sports) and feeling at one with natural settings. On a more metaphysical level, it can be represented by harmony with the cosmos, developing a balanced state of mind, reaching sport ataraxia and Nirvana, or experiencing catharsis.

In conclusion, we argue that meaning in sport (and more in "sport") is very often related to achieving a goal (winning), so it is identified with this process. Concretely (for elite races, especially), it could be as follows: the meaning of a bicycle race is presented by finishing the activity at the demanded time and place. However, we must remember that the journey (in the case of a bicycle race, this image is very illustrative) should be meaningful, as well. The Buddhist concepts of the "journey without goal," or the (slightly less strict) statement "even the journey can be the goal," seem to be in opposition to the situations typical for sports events. However, this attitude presents just one possible (although common) approach to the meaning of sport races. The journey presents the substance of the meaning of movement (because without the journey a [bicycle] racer cannot participate in his movement, while accomplishing the goal is not necessary for this participation). Per 
the approach based on holism, the meaning of the cyclist's movement is accomplished in the process of embarking on the journey, although crossing the finish line undoubtedly crowns the effort.

Movement is a perpetual and never-ending issue. The same goes for the matter through which movement serves as a vehicle (in a broad sense). The meaning of movement is contained in the movement itself, and it presents an objective issue. Sports movement has its rules and demonstrates itself as a cultural phenomenon, but it poses an extremely short episode in the process of motion (in the context of the history of mankind). The exhausted winner of the Tour de France probably never philosophized on the subject of the meaning of human movement. However, through any of his actions he repeatedly and unknowingly establishes this problem. Although a sportsman/woman (in the majority of cases) does not look for any deeper reflection, he/she can become (without producing any willful effort) the object of these reflections (Sheehan 1978; McDougall 2010).

\section{REFERENCES}

Bednář, M. (2009). Pohyb člověka na biodromu. Cesta životem (nejen) z pohledu kinantropologie [Human Motion on the Biodrome: A Way Through Life (Not Just) from the Perspective of Kinanthropology]. Praha: Karolinum. p. 190. ISBN 978-80-246-1665-0.

Camus, A. (1955). The Myth of Sisyphus and Other Essays. New York, NY: Vintage Books.

Crum, B. (1986). Concerning the quality of the development of knowledge in sport pedagogy. Journal of Teaching in Physical Education, 5, 211-220.

Edgar, A. (2013). Hermeneutics of sport. Sport, Ethics and Philosophy, 7(1), 140-167.

Ellfeldt, L. \& Metheny, E. (1958). Movement and meaning: Development of a general theory. Research Quarterly of the American Association for Health, Physical Education, \& Recreation, 29(3), 26-273.

Frankl, V.E. (1988). The Will to Meaning: Foundations and Applications of Logotherapy. New York, NY: New American Library.

Frankl, V.E. (2006). Man's Search for Meaning: An Introduction to Logotherapy. Boston, MA: Beacon Press.

Frias, F. \& Monfort, X. (2015). A hermeneutical analysis of the internalist approach in the philosophy of sport. Physical Culture and Sport. Studies and Research, 67(1), 5-12.

Frias, F.J.L. \& Edgar, A. (2016). Hermeneutics and sport. Sport, Ethics and Philosophy, 10(4), 343-348.

Harris, J.C. (1981). Hermeneutics, interpretive cultural research, and the study of sports. Quest, 33(1), 72-86.

Hawkins, A. (1987). On the role of hermeneutics in sport pedagogy: A reply to Crum. Journal of Teaching in Physical Education, 6(4), 67.

Hay, W.H. (1952). Nicolaus Cusanus: The structure of his philosophy. The Philosophical Review, 61(1), 14-25.

Heidegger, M. (2008). Being and Time. Translated by John MacQuarrie \& Edward Robinson. New York, NY: Harper \& Row Publishers.

Hendl, J. (2005) Kvalitativni výzkum: Základní metody a aplikace. [Qualitative Research: Basic Methods and Applications]. Praha: Portál.

Hurych, E. (2010). Možnosti transferu od teorie k praxi v některých oblastech filosofické Kinantropologie [The possibilities of transfer from theory to practice in some areas of philosophical kinanthropology]. Télesná kultura, 33(3), 7-26. ISSN 1211-6521.

Charles, J.M. (1996). Scholarship reconceptualized: The connectedness of kinesiology. Quest, 48(2), 152-164.

Ilundáin-Agurruza, J. (2014). Skillful striving: Holism and the cultivation of excellence in sports and performative endeavors. Sport, Ethics and Philosophy, Special Issues, 8(3-4), 221-342.

Jirásek, I. \& Hurych, E. (2012). Pain and suffering in sport. Human Movement, 13(2), 185-189. doi: 10.2478/v10038012-0021-6

Jurkevič, J. (2002). Germenevtičeskije idei v vostočnoslavjanskoj filisofskoj tradicii [Hermeneutic Ideas in Yugoslavian Philosophical Tradition]. Charkov: Charkovskij nacional'nyj universitet.

Kirk, D. (1992). Physical education, discourse, and ideology: Bringing the hidden curriculum into view. Quest, 44(1), $35-56$.

Kosiewicz, J. (2009). Sport and Philosophy (From Methodology to Ethics). Warsaw: Wydawnictvo BK.

Kretchmar, S. (2005). Practical Philosophy of Sport and Physical Activity. Champaign, IL: Human Kinetics.

Loland, S. (2006). Three approaches to the study of pain in sport. In S. Loland, B. Kirstad, \& I. Waddington (Eds.), Pain and Injury in Sport (pp. 49-62). London: Routledge.

Machovec, M. (2012). Smysl lidské existence [Sense of Human Existence]. Praha: Akropolis. 
McDougall, C. (2010). Born to Run. New York, NY: Alfred A. Knopf.

McFee, G. (2013). Making sense of the philosophy of sport. Sport, Ethics and Philosophy, 7(4), 412-429.

Metheny, E. (1964). Only by moving their bodies. Quest, 2(1), 47-51.

Metheny, E. (1967). How does a movement mean? Quest, 8(1), 1-6.

Mikihiri, S., Jordan, J.S., \& Funk, D.C. (2015). Distance running events and life satisfaction: A longitudinal study. Journal of Sport Management, 29(4), 347-361.

Nemec, M. (2010). Agonistika a názorový pluralizmus gréckych antických autorov [Agonism and opinion relativism of Greek ancient authors]. Telesná výchova \& šport, 20(4), 6-10.

Oborný, J. \& Vrtiaková, B. (2014). Philosophical and ethical reflection of sport in the context of sport humanistics. Acta Facultatis Educationis Physicae Universitatis Comenianae, 54(2), 43-54.

Oeming, M. (2006). Contemporary Biblical Hermeneutics: An Introduction. Burlington, VT: Ashgate Publishing Comp.

Osborne, G.R. (1991). The Hermeneutical Spiral: A Comprehensive Introduction to Biblical Interpretation. Downers Grove, IL: Inter Varsity Press.

Pačesová, P. (2014) Perception of aesthetic aspects of human body in the context of motives and physical activity. Acta Facultatis Educationis Physicae Universitatis Comenianae, 54(1), 47-48.

Seipel, Ø. (2006). The meanings of sport: Fun, health, beauty or community? Sport in Society: Cultures, Commerce, Media, Politics, 9(1), 51-70.

Sheehan, G. (1978). Running \& Being: The Total Experience. New York, NY: Simon \& Schuster.

AUTHOR'S ADDRESS: $\quad$ Ivo Jirasek

Palacky University

Faculty of Physical Culture

77111 Olomouc

Tr. Miru 115

Czech Republic

E-mail: ivo.jirasek@upol.cz

Received: 9 April 2018; Accepted: 15 June 2018 